\title{
EVIDENCE-BASED PRACTICES THAT DEAL WITH WORK-FAMILY CONFLICT AND ENRICHMENT: SYSTEMATIC LITERATURE REVIEW
}

\author{
Tadas VADVILAVIČIUS ${ }^{*}$, Aurelija STELMOKIENE் \\ Department of Psychology, Faculty of Social Sciences, Vytautas Magnus University, Kaunas, Lithuania
}

Received 10 March 2020; accepted 18 August 2020

\begin{abstract}
Work and family are the most important aspects in everyday life that interact with each other simultaneously. The interaction between work and family may cause both negative and positive outcomes that is why scientists and practitioners are seeking to understand how to control them. The purpose of this article was to review existing literature on work-family conflict and enrichment interventions. We conducted a systematic literature review to investigate the evidence-based practises that dealt with reduction of work-family conflict and increase in work-family enrichment. After the screening, 12 articles from 699 unique studies were selected for the in-depth analysis. 11 out of 12 represented interventions confirmed significant positive results about the reduction of work-family conflict or increase in work-family enrichment. It is not surprising that organizations quite often choose training/workshop as the most suitable intervention. Similarly, only one scientific article presented the intervention that used real organizational change to reduce work-family conflict. Additionally, only one intervention was oriented towards the positive side of work family interaction - increase in work-family enrichment. Finally, practical implications and future research directions are proposed in the discussion.
\end{abstract}

Keywords: work-family interaction, work-family conflict, work-family enrichment, work-family balance, intervention, systematic literature review.

JEL Classification: I31, M12.

\section{Introduction}

The relationship between work and family (or family and work) becomes one of the most relevant aspects of everyday life to all people around the world, that is why practitioners and scientists are seeking to understand the way work and family interact with each other (McNamara et al., 2013; Vieira et al., 2018; Wang et al., 2017). The main focus is on the search for the answer, how could two important life aspects enrich each other instead of conflicting. For the last few decades, three main topics in the work-family research field occurred - work-family conflict (WFC; or family-work conflict, FWC), work-family enrichment (WFE; or family-work enrichment, FWE) and work-family balance (WFB; or family-work balance, FWB). It is important to highlight that interaction between work and family is double-faced, which means work can affect family and vice versa but, in this paper, we focus more on work to family interaction (although some results or ideas may be applied for both ways).

From the beginning of work-family research era, scientists focused on WFC which is defined as "an individual's difficulties in fulfilling simultaneous and/or competing demands from multiple and salient roles [work and family], resulting in the depletion of his or her limited timeand energy-related resources" (Vieira et al., 2018, p. 153). Researchers argue that WFC is a significant phenomenon in human resource management because it influences most of the employees and organizations all around the world (McNamara et al., 2013). For example, WFC is associated with lower job and life satisfaction (Adams et al., 1996; Zhao et al., 2019; Zarei et al., 2016), higher levels of work stress and burnout (Smith et al., 2018; Farradinna \& Halim, 2016). WFC is also negatively related to the continuance and normative organizational commitment (Farradinna \& Halim, 2016) and positively related to turnover intentions (Haar, 2004; Nohe \& Sonntag, 2014). With reference to Michel's et al. (2011) meta-analysis the main antecedents of WFC are higher levels of global job stressors, work role overload/conflict/demands/ambiguity, job involvement, work centrality and task variety and lower levels of organizational/supervisor/coworker support, job autonomy, and family-friendly organization.

${ }^{*}$ Corresponding author. E-mail: tadas.vadvilavicius@vdu.lt

Copyright @ 2020 The Author(s). Published by Vilnius Gediminas Technical University.

This is an Open Access article distributed under the terms of the Creative Commons Attribution License (http://creativecommons.org/licenses/by/4.0/), which permits unrestricted use, distribution, and reproduction in any medium, provided the original author and source are credited. 
Recently, researchers started to question if work and family can positively impact each other. Moreover, they initiated studies on how work can enrich family life. WFE is defined as "the extent to which experiences in one life role [work] enhance the quality of performance and experiences in another life role [family], either directly, or indirectly through their influence on positive affect" (Vieira et al., 2018, p. 153). WFE predicts higher affective and continuance organizational commitment (Wayne et al., 2006; McNall et al., 2010), is positively associated with job satisfaction (McNall et al., 2010), work engagement, organizational citizenship behavior, life satisfaction (Zhang et al., 2018) and negatively related to turnover intentions (McNall et al., 2009; Zhang et al., 2018). Lapierre's et al. (2018) meta-analysis revealed 5 organizational features as the most important antecedents of WFE: higher levels of social support at work, family-friendly organizational policies, work autonomy, family-friendly organizational culture and lower level of job insecurity.

Finally, inspired by positive psychology, researchers launched discussions about WFB that could be characterized as low level of WFC and high level of WFE (Casper et al., 2018; Valcour, 2007; Vieira et al., 2018; Weinzimmer et al., 2017; Morganson et al., 2014; Moazami-Goodarzi et al., 2018). Although different descriptions of WFB are used in work-family interaction literature, we believe that each person could experience both conflict and enrichment simultaneously that is why it is important to focus on both WFC and WFE. Researches confirm that WFB is associated with higher levels of employees job satisfaction, psychological well-being, organizational commitment and a lower level of employees' turnover intentions (McNamara et al., 2013; Pecino et al., 2018; Mazzucchelli, 2017; Cho \& Allen, 2019; Weinzimmer et al., 2017). Therefore, practitioners (human resource managers and leaders) are interested in how to increase WFB which has a crucial positive effect on employees and organizations.

As far as antecedents and consequences of WFC and WFE are known, practitioners are trying to adapt the scientific knowledge into practice. However, to be sure that interventions will pay off, they should seek to apply evidence-based practices into organizations' life. It is also important to propose specific guidelines for the implementation of integrated WFB interventions and recommendations to organizational psychologists, HR practitioners or business counselors based on the research of WFC and WFE interventions. Therefore, the main goal of this systematic-review is to identify and describe evidence-based interventions that could be applied to organizational practice in order to decrease WFC and increase WFE and WFB. Towards achieving the goal, two main criteria were chosen for literature search and selection - articles should present WFC and/or WFE interventions that were applied in organizational settings and provide quantitative data about the effectiveness of interventions. Finally, insights for future research and practical implications about what can be done managing work-life interaction are proposed in the article.

\section{Methods}

\section{Search procedures}

Based on the similar practice of other authors in the topic and the goal of this systematic-review key terms were identified (work-family conflict, work-family enrichment, work-family balance, work-life conflict, worklife enrichment, work-life balance, intervention, training, experiment, quasi-experiment) and used to search relevant articles in electronic databases. Keywords were combined in groups until all possible combinations were exhausted. Quantitative studies and theses that reported any kind of intervention that dealt with WFC and/ or WFE were searched. Articles written both in English and Lithuanian were accepted. International databases were used to search for articles: PsycARTICLES, ScienceDirect, Academic Search Complete. Search via using key terms revealed 699 unique studies. By this task the first step in order to identify potentially relevant studies, scanning of titles and abstracts was completed. The scanning of titles and abstracts was used as a quick way to look through the research ideas, methodology and results in the particular topic. 44 studies in total were identified as relevant and included in further analysis. The main criteria to select an article for the in-depth analysis was the applicability of intervention into organizational practice. Mainly, we looked for interventions that were examined in a real organization but not in a laboratory setting or field, e.g. Clayton et al. (2017) reported a field experiment on how does exercise can reduce WFC and the study was not selected as a suitable study to analyze. Besides, studies were excluded if they didn't report quantitative data about the effectiveness of intervention (the change of WFC or WFE level after intervention). For example, a few studies reported using the STAR program as one to reduce WFC, but the research aim didn't include and given results didn't report any results about the effectiveness of the STAR program. Other studies collected only qualitative data. Qualitative studies were omitted with reference to researchers who stated that qualitative methods are not standardized, data and results are considered as less reliable and harder to generalize for population (Leung, 2015), besides, they suffer from potential researcher's bias (Noble \& Smith, 2015). These disadvantages were very important for the main goal of this systematic-review. So, only 10 studies from 44 relevant ones, which presented interventions' effect size, were selected for deeper analysis. Based on the other researchers' experience (e.g. Brown \& Clark, 2017) reference lists of 10 selected articles were also scanned to look for an article that could be relevant. While scanning the titles, 2 potential articles were found. After scanning abstracts and the whole papers, these 2 extra relevant studies were chosen to include in the final data set. In all, 12 studies were selected for the final analysis (see Table 1). 
Table 1. The main information about the research used in the systematic-review

\begin{tabular}{|c|c|c|c|}
\hline Author (-s) & Intervention & Participants & Main findings \\
\hline $\begin{array}{l}\text { Haslam } \\
\text { et al., } 2013\end{array}$ & $\begin{array}{l}\text { Researchers used Workplace Triple P } \\
\text { intervention in which participants were taught } \\
\text { a range of parenting strategies to encourage } \\
\text { desirable behaviour and gave three telephone } \\
\text { consultations to help promote self-regulation in } \\
\text { children and decrease problem behaviour. }\end{array}$ & $\begin{array}{l}107 \text { teachers }(76.6 \% \\
\text { female); mean age }- \\
40.6 \text { two groups }-1 \\
\text { experimental }(n=55) \text { and } \\
1 \text { control group }(n=52) ;\end{array}$ & $\begin{array}{l}\text { The intervention was effective at } \\
\text { reducing both WFC and FWC in } \\
\text { teachers' sample. }\end{array}$ \\
\hline $\begin{array}{l}\text { Kelly et al., } \\
2011\end{array}$ & $\begin{array}{l}\text { The Results-Only Work Environment (ROWE) } \\
\text { training program was implemented in } \\
\text { organization. }\end{array}$ & $\begin{array}{l}608 \text { employees }(50 \% \\
\text { female), mean age }-32 ; \\
\text { two groups - } \\
1 \text { experimental and } \\
1 \text { control group; }\end{array}$ & $\begin{array}{l}\text { The study revealed that the ROWE } \\
\text { program reduced WFC. }\end{array}$ \\
\hline $\begin{array}{l}\text { Heskiau, } \\
2017\end{array}$ & $\begin{array}{l}\text { In the experiment, participants received a } \\
\text { WFE training, while in the control group, } \\
\text { participants received training on the lifestyle } \\
\text { topics of sleep, exercise and nutrition at work } \\
\text { and outside of work. }\end{array}$ & $\begin{array}{l}163 \text { employees ( } 81.6 \% \\
\text { female); mean age }-43.16 ; \\
\text { two groups - } \\
1 \text { experimental group and } \\
1 \text { control; }\end{array}$ & $\begin{array}{l}\text { WFE training had an impact on } \\
\text { increased enrichment experiences } \\
\text { and enrichment self-efficacy. }\end{array}$ \\
\hline $\begin{array}{l}\text { Albertsen } \\
\text { et al., } 2014\end{array}$ & $\begin{array}{l}\text { Three types of intervention were conducted } \\
\text { in which participants had to rethink their } \\
\text { workings habits, hours or working resources. }\end{array}$ & $\begin{array}{l}840 \text { participants }(90 \% \\
\text { female); four groups }- \\
3 \text { experimental }(n=135 \\
259 \text { and } 99) \text { and } 1 \text { control } \\
\text { group }(n=347) ;\end{array}$ & $\begin{array}{l}\text { All experimental groups showed a } \\
\text { positive impact of intervention on } \\
\text { decreasing WFC, but the highest } \\
\text { impact was in the group, in which } \\
\text { participants had the opportunity } \\
\text { to select days when they wanted to } \\
\text { work. }\end{array}$ \\
\hline $\begin{array}{l}\text { Kiburz et al., } \\
2017\end{array}$ & $\begin{array}{l}\text { The two-week mindfulness-based training } \\
\text { program was designed for the study. }\end{array}$ & $\begin{array}{l}102 \text { participants (79.4 } \\
\text { females); mean age }-45.01 ; \\
\text { two experimental groups; }\end{array}$ & $\begin{array}{l}\text { Results revealed that mindfulness- } \\
\text { based training could reduce WFC. }\end{array}$ \\
\hline $\begin{array}{l}\text { Wilson } \\
\text { et al., } 2007\end{array}$ & $\begin{array}{l}\text { Three training groups were organized in the } \\
\text { research: Group A - maintain alertness with a } \\
\text { focus on diet and exercise; Group B focused on } \\
\text { diet, exercise and sleep both at home and work, } \\
\text { and with managing time and priorities between } \\
\text { work and family; Group C - same focus as in } \\
\text { B group but participants were asked to attend } \\
\text { with their partners / spouses. }\end{array}$ & $\begin{array}{l}432 \text { employees in the final } \\
\text { sample (all male); mean } \\
\text { age - 41.33; }\end{array}$ & $\begin{array}{l}\text { WFC scores declined in all three } \\
\text { groups, but the highest reduction } \\
\text { was in group } C \text { when the family had } \\
\text { been involved in the training as well. }\end{array}$ \\
\hline $\begin{array}{l}\text { Slutsky } \\
\text { et al., } 2019\end{array}$ & $\begin{array}{l}\text { Mindfulness workshop was used as an } \\
\text { intervention to reduce WFC }\end{array}$ & $\begin{array}{l}60 \text { employees }(66.7 \% \\
\text { female); mean age }-30.52 ; \\
\text { Two groups }- \\
1 \text { experimental }(\mathrm{n}=31) \\
\text { and } 1 \text { control group } \\
(\mathrm{n}=29) ;\end{array}$ & $\begin{array}{l}\text { Results suggested that mindfulness } \\
\text { training reduced WFC. }\end{array}$ \\
\hline $\begin{array}{l}\text { Michel et al., } \\
2014\end{array}$ & $\begin{array}{l}\text { Mindfulness-based intervention, training } \\
\text { on how to use mindfulness as a cognitive- } \\
\text { emotional segmentation strategy, was used. }\end{array}$ & $\begin{array}{l}246 \text { participants }(71.1 \% \\
\text { female); mean age }- \\
41.41 ; \text { two groups }-1 \\
\text { experimental }(n=96) \text { and } \\
1 \text { control group }(n=150) ;\end{array}$ & $\begin{array}{l}\text { Results showed that Mindfulness- } \\
\text { based intervention had a positive } \\
\text { impact on promoting WFB and } \\
\text { reducing WFC. }\end{array}$ \\
\hline $\begin{array}{l}\text { Hammer } \\
\text { et al., } 2016\end{array}$ & $\begin{array}{l}\text { The integrated STAR training program was } \\
\text { used as an experimental condition to reduce } \\
\text { work-family conflict. }\end{array}$ & $\begin{array}{l}1524 \text { employees; mean } \\
\text { age }-34.06 \text {; final analysis } \\
\text { with two groups }-1 \\
\text { experimental }(\mathrm{n}=725) \\
\text { and } 1 \text { control group }(\mathrm{n}= \\
799) ;\end{array}$ & $\begin{array}{l}\text { No significant STAR program's effects } \\
\text { for WFC were observed. }\end{array}$ \\
\hline $\begin{array}{l}\text { Kelly et al., } \\
2014\end{array}$ & $\begin{array}{l}\text { STAR program sessions, computer-based } \\
\text { training, and self-monitoring activities were } \\
\text { conducted as an intervention method. The } \\
\text { intervention program was designed to transit } \\
\text { participants from a time-based to result-based } \\
\text { work culture. }\end{array}$ & $\begin{array}{l}496 \text { employees; final } \\
\text { analysis with two groups - } \\
1 \text { experimental }(\mathrm{n}=348) \\
\text { and } 1 \text { control group }(\mathrm{n}= \\
346) ;\end{array}$ & $\begin{array}{l}\text { Results revealed that the STAR } \\
\text { program could reduce perceived } \\
\text { WFC in an organization. Also, } \\
\text { employees who had greater family } \\
\text { demands and lower supervisor } \\
\text { support benefited more from the } \\
\text { intervention. }\end{array}$ \\
\hline
\end{tabular}


End of Table 1

\begin{tabular}{|l|l|l|l|}
\hline Author (-s) & \multicolumn{1}{|c|}{ Intervention } & \multicolumn{1}{c|}{ Participants } & \multicolumn{1}{c|}{ Main findings } \\
\hline $\begin{array}{l}\text { Posard et al., } \\
2013\end{array}$ & $\begin{array}{l}\text { The intervention was focused on rearranging } \\
\text { the schedule of U.S. Army soldier work-day. }\end{array}$ & $\begin{array}{l}\text { 1445 soldiers (90\% male); } \\
1 \text { experimental group; }\end{array}$ & $\begin{array}{l}\text { Results revealed that with rearranged } \\
\text { schedule WFC had decreased for } \\
\text { junior-enlisted personnel, but had no } \\
\text { impact on other sample groups. }\end{array}$ \\
\hline $\begin{array}{l}\text { Olson et al., } \\
2015\end{array}$ & $\begin{array}{l}\text { Researchers conducted a 12-month long } \\
\text { experiment in which the STAR program was } \\
\text { implemented. The intervention program was } \\
\text { designed to transit participants from a time- } \\
\text { based to result-based work culture. }\end{array}$ & $\begin{array}{l}474 \text { employees (27.6\% } \\
\text { female); (two groups - } 1 \\
\text { experimental (n = 234) } \\
\text { and 1 control group (n }= \\
240) ;\end{array}$ & $\begin{array}{l}\text { Results revealed that WFC decreased, } \\
\text { but results were mediated by } \\
\text { increased control over work hours } \\
\text { (structuring work). }\end{array}$ \\
\hline
\end{tabular}

\section{Results}

Most of the studies, that were selected and analyzed, (11 out of 12) used specific trainings/workshops as an intervention to reduce WFC/increase WFE and only one used real organizational change (rearrangement of work-day schedule). Also, it is important to emphasize that 10 out of 12 studies analyzed the impact of intervention on WFC, while only 1 article revealed an effect of intervention on WFE and 1 - on both WFB and WFC. As can be seen from the first table the STAR program was quite popular as it was used as an intervention method to decrease WFC in 3 studies. Besides, 3 other studies described Mindfulness (-based) training as a suitable intervention material to deal with WFC and WFB. The remaining 6 studies applied other programs/methods that varied from trainings of specific parenting strategies to focus on diet, exercise, and sleep, together with time and priorities management. The number of participants in the studies varied from 60 to 1524 while most of them were women and elder people (as far as it can be seen from given information about participants). Finally, 11 studies showed positive results of WFC/WFE interventions and confirmed their effectiveness.

\section{Discussion}

A systematic literature review revealed that both WFC and WFE can be changed (decreased/increased) by specific interventions. From all 12 studies that had been selected for analysis, 11 studies showed that intervention could be effective for WFC reduction/WFE increase, while the main intervention method was training/workshop. In an annual industry training report of 2019, training expenditures reached 83 billion U.S. dollars per year (Freifeld, 2019). So, it seems that this type of intervention is the most acceptable for organizations.

Two specific programs/theories were researched the most while analyzing interventions for work-family interaction- the STAR program and Mindfulness (-based) training. The STAR (Support. Transform. Achieve. Results) program was created as a helpful tool for workplace teams to find ways to reduce WFC and increase productivity. Two main aspects of the STAR program are a) exercising employees' ability to redesign their work and b) train supervisors on how to support a family and personal life. There are more than 14 organizational aspects identified as significant antecedents for both WFC and WFE and the STAR program covers 2 of them: supervisor support and job autonomy. For more information about the STAR program and program materials visit the official website - https://workfamilyhealthnetwork.org/toolkits-achieve-workplace-change. Meanwhile, mindfulness (-based) training is one of the fastest-growing training industries which is spreading through different disciplines, workplace as well (Good et al., 2015; Slutsky et al., 2019; Shapiro et al., 2006). Mindfulness is focused on the development of participant's ability to be more aware, but nonjudgmental of surrounding and to fully experience the present moment (Kiburz et al., 2017; Michel et al., 2014). Michel et al. (2014) propose that mindfulness practice can be used as a strategy to cope with work-related cognitions, emotions and help to shape boundaries between work and private life. Although mindfulness (as an ability) is more seen as a personal employee characteristic and not organizational factor, it is considered that mindfulness (-based) training may be applied to organizational practice and could have a positive effect on employees who suffer from WFC.

We should admit that we managed to find only one study that addressed intervention for increasing WFE. As it was stated earlier, WFC influenced most of the employees all around the world (McNamara et al., 2013) and the impact was negative both for employees and organization. Maybe, therefore, organizations pay more attention to this phenomenon hoping to reduce negative effects. Meanwhile, WFE is more related to positive outcomes for employees and organizations (e.g. higher job and life satisfaction) and proposes added value to organizations. So, WFE also deserves active actions from organization side. It could be that after dealing with urgent negative aspects (fighting a fire) organizations would give their attention to developmental issues as well.

While planning to apply any of previously presented interventions into practice, HR specialists, organizational psychologists etc., should consider that research of interventions was conducted in different socio-economic and cultural context. No matter that results are promising, it should be noted that different economic situation in the country, different values may complicate the application of identified interventions. For example, one of the aspects in 
STAR program is to train employees how to redesign their work. It is possible that it would be harder to fulfil this task in countries where such cultural values as restrain (described in Hofstede cultural model (Minkov \& Hofstede, 2011)) are higher because in these countries people are more strict and tend to follow norms and traditions. Therefore, people here should be less interested in learning the new ways of doing their work. On the other hand, in cultures where power distance value is high (high acceptance of hierarchy in the society (Minkov \& Hofstede, 2011)) managers should be less interested in learning how to support employees' personal life. Although these assumptions are just theoretical, practitioners should consider possible differences between the original country where research was implemented and their own country.

Finally, it should be noted that different additional factors (e.g. organizational climate, support system, employees' self-efficacy, motivation, etc.) should be taken into account while applying intervention into practice and hoping the training to be effective (Blume et al., 2010; Durbin et al., 2019; Moen et al., 2016; Zarei et al., 2016). Besides, practitioners want to be sure that after trainings/ workshops employees will transfer their knowledge and skills into a workplace. Moreover, as it was mentioned earlier, there were more than 14 organizational features that could be important for dealing with WFC or WFE. So, training/workshop is not the only way for intervention and application of those features to the organizational life. For example, family-friendly policies can be applied only by restructuring rules inside the organization and training could be used as an additional way to introduce new organizational rules to employees; rearrangement of work is necessary for work role overload management. These examples illustrate that organizations could do more to work with WFC and/or WFE not only organize training sessions for their employees.

\section{Practical implications and future research}

This systematic literature review showed that different interventions could be effective for WFC reduction and WFE and WFB increase in organizations. Organizations that deal with a high level of employees' perceived WFC can successfully apply the STAR or ROWE programs, organize Mindfulness (-based) training sessions for their personnel. Organizational change (rearranged work schedule, transition from time-based to result-based work culture) can also be used as the evidence-based practice for WFC reduction. However, future research should pay more attention to ways how to increase WFE and WFB. WFE and WFB are noteworthy phenomena that can have a huge positive impact both on employees and organizations. Besides, we highlight the importance to research the effectiveness of a wider range of intervention methods, like new organizational policies and culture development, work restructuration/development, application of different team/coworkers/leaders' support systems, etc. As cultural differences were identified as an important contextual factor in the work family interaction research, we recommend to conduct cross-cultural studies, that should help to test if presented interventions are culturally independent and could be applied in different political, geographical, economic, cultural conditions.

\section{Conclusions}

10 evidence-based interventions that could be applied to organizational practice in order to decrease WFC were identified through systematic literature-review. STAR program and Mindfulness-based trainings were the most popular ones used for WFC reduction. Meanwhile only 1 intervention that dealt with an increase of WFE and WFB was found.

\section{Acknowledgements}

This research was funded by the European Social Fund under the No 09.3.3-LMT-K-712 "Development of Competencies of Scientists, other Researchers, and Students through Practical Research Activities" measure.

\section{Funding}

This work was supported by the European Social Fund under the No 09.3.3-LMT-K-712 "Development of Competencies of Scientists, other Researchers, and Students through Practical Research Activities" measure.

\section{Author contributions}

We confirm that all listed authors have contributed significantly to the manuscript and consent to their names on the manuscript.

\section{Disclosure statement}

There are no conflicts of interest between the author and Editorial Board of the Journal, between the author and research sponsor, between the author and the publisher. We confirm that the manuscript or the data have not been published previously and they are not under consideration for publication elsewhere. The whole document is signed by all authors.

\section{References}

Adams, G. A., King, L. A., \& King, D. W. (1996). Relationships of job and family involvement, family social support, and work-family conflict with job and life satisfaction. Journal of Applied Psychology, 81(4), 411-420. https://doi.org/10.1037/0021-9010.81.4.411

Albertsen, K., Garde, A. H., Nabe-Nielsen, K., Hansen, Å. M., Lund, H., \& Hvid, H. (2014). Work-life balance among shift workers: results from an intervention study about self-rostering. International Archives of Occupational and Environmental Health, 87(3), 265-274.

https://doi.org/10.1007/s00420-013-0857-x 
Blume, B. D., Ford, J. K., Baldwin, T. T., \& Huang, J. L. (2010). Transfer of training: A meta-analytic review. Journal of Management, 36(4), 1065-1105.

https://doi.org/10.1177/0149206309352880

Brown, T. J., \& Clark, C. (2017). Employed parents of children with disabilities and work family life balance: A literature review. Child \& Youth Care Forum, 46(6), 857-876.

https://doi.org/10.1007/s10566-017-9407-0

Casper, W. J., Vaziri, H., Wayne, J. H., DeHauw, S., \& Greenhaus, J. (2018). The jingle-jangle of work-nonwork balance: A comprehensive and meta-analytic review of its meaning and measurement. Journal of Applied Psychology, 103(2), 182. https://doi.org/10.1037/apl0000259

Cho, E., \& Allen, T. D. (2019). The transnational family: A typology and implications for work-family balance. Human Resource Management Review, 29(1), 76-86.

https://doi.org/10.1016/j.hrmr.2018.01.001

Clayton, R. W., Thomas, C. H., Schaffer, B. S., Stratton, M., Garrison, E., \& Mathews, L. G. (2017). Exercise and work-family conflict: a field experiment. Journal of Managerial Psychology, 32(3), 225-238. https://doi.org/10.1108/JMP-08-2015-0324

Durbin, D. R., House, S. C., Meagher, E. A., \& Rogers, J. G. (2019). The role of mentors in addressing issues of work-life integration in an academic research environment. Journal of Clinical and Translational Science, 3(6), 302-307. https://doi.org/10.1017/cts.2019.408

Farradinna, S., \& Halim, F. W. (2016). The consequences of work-family conflict, burnout and organizational commitment among women in Indonesia. Procedia-Social and Behavioral Sciences, 219, 241-247.

https://doi.org/10.1016/j.sbspro.2016.05.012

Freifeld, L. (2019). 2019 training industry report. Training: the official publication of training magazine network. https://trainingmag.com/sites/default/files/2019_industry_report.pdf

Good, D. J., Lyddy, C. J., Glomb, T. M., Bono, J. E., Brown, K. W., Duffy, M. K., \&... Lazar, S. W. (2015). Contemplating mindfulness at work. Journal of Management, 42(1), 114-142. https://doi.org/10.1177/0149206315617003

Haar, J. M. (2004). Work-family conflict and turnover intention: Exploring the moderation effects. New Zealand Journal of Psychology, 33(1), 35-39.

Hammer, L. B., Johnson, R. C., Crain, T. L., Bodner, T., Kossek, E. E., Davis, K. D., ... \& Berkman, L. (2016). Intervention effects on safety compliance and citizenship behaviors: Evidence from the work, family, and health study. Journal of Applied Psychology, 101(2), 190-208.

https://doi.org/10.1037/apl0000047

Haslam, D. M., Sanders, M. R., \& Sofronoff, K. (2013). Reducing work and family conflict in teachers: A randomised controlled trial of Workplace Triple P. School Mental Health, 5(2), 70-82. https://doi.org/10.1007/s12310-012-9091-z

Heskiau, R. (2017). Work-family enrichment training: promoting transferability of resources across life domains [Doctoral dissertation, University of Toronto]. Toronto, Canada. https://doi.org/10.5465/AMBPP.2018.12586abstract

Kelly, E. L., Moen, P., \& Tranby, E. (2011). Changing workplaces to reduce work-family conflict: Schedule control in a whitecollar organization. American Sociological Review, 76(2), 265290. https://doi.org/10.1177/0003122411400056

Kelly, E. L., Moen, P., Oakes, J. M., Fan, W., Okechukwu, C., Davis, K. D., ... \& Mierzwa, F. (2014). Changing work and work-family conflict: Evidence from the work, family, and health network. American Sociological Review, 79(3), 485516. https://doi.org/10.1177/0003122414531435
Kiburz, K. M., Allen, T. D., \& French, K. A. (2017). Work-family conflict and mindfulness: Investigating the effectiveness of a brief training intervention. Journal of Organizational Behavior, 38(7), 1016-1037. https://doi.org/10.1002/job.2181

Lapierre, L. M., Li, Y., Kwan, H. K., Greenhaus, J. H., DiRenzo, M. S., \& Shao, P. (2018). A meta-analysis of the antecedents of work-family enrichment. Journal of Organizational Behavior, 39(4), 385-401. https://doi.org/10.1002/job.2234

Leung, L. (2015). Validity, reliability, and generalizability in qualitative research. Journal of Family Medicine and Primary Care, 4(3), 324. https://doi.org/10.4103/2249-4863.161306

Mazzucchelli, S. (2017). Flexibility and work-family balance: a win-win solution for companies? The case of Italy. International Review of Sociology, 27(3), 436-456. https://doi.org/10.1080/03906701.2017.1377411

McNall, L. A., Masuda, A. D., \& Nicklin, J. M. (2009). Flexible work arrangements, job satisfaction, and turnover intentions: the mediating role of work-to-family enrichment. The Journal of Psychology, 144(1), 61-81. https://doi.org/10.1080/00223980903356073

McNall, L. A., Nicklin, J. M., \& Masuda, A. D. (2010). A metaanalytic review of the consequences associated with workfamily enrichment. Journal of Business and Psychology, 25(3), 381-396. https://doi.org/10.1007/s10869-009-9141-1

McNamara, T. K., Pitt-Catsouphes, M., Matz-Costa, C., Brown, M., \& Valcour, M. (2013). Across the continuum of satisfaction with work-family balance: Work hours, flexibility-fit, and work-family culture. Social Science Research, 42(2), 283-298. http://dx.doi.org/10.1016/j.ssresearch.2012.10.002

Michel, A., Bosch, C., \& Rexroth, M. (2014). Mindfulness as a cognitive-emotional segmentation strategy: An intervention promoting work-life balance. Journal of Occupational and Organizational Psychology, 87(4), 733-754.

https://doi.org/10.1111/joop.12072

Michel, J. S., Kotrba, L. M., Mitchelson, J. K., Clark, M. A., \& Baltes, B. B. (2011). Antecedents of work-family conflict: A meta-analytic review. Journal of Organizational Behavior, 32(5), 689-725. https://doi.org/10.1002/job.695

Minkov, M., \& Hofstede, G. (2011). The evolution of Hofstede's doctrine. Cross Cultural Management: An International Journal, 18(1), 10-20. https://doi.org/10.1108/13527601111104269

Moazami-Goodarzi, A., Nurmi, J. E., Mauno, S., Aunola, K., \& Rantanen, J. (2018). Longitudinal latent profiles of work-family balance: Examination of antecedents and outcomes. International Journal of Stress Management, 26(1), 65-77. https://doi.org/10.1037/str0000093

Moen, P., Kelly, E. L., Fan, W., Lee, S. R., Almeida, D., Kossek, E. E., \& Buxton, O. M. (2016). Does a flexibility/support organizational initiative improve high-tech employees' wellbeing? Evidence from the work, family, and health network. American Sociological Review, 81(1), 134-164. https://doi.org/10.1177/0003122415622391

Morganson, V. J., Litano, M. L., \& O’Neill, S. K. (2014). Promoting work-family balance through positive psychology: A practical review of the literature. The Psychologist-Manager Journal, 17(4), 221. https://doi.org/10.1037/mgr0000023

Noble, H., \& Smith, J. (2015). Issues of validity and reliability in qualitative research. Evidence-Based Nursing, 18(2), 34-35. https://doi.org/10.1136/eb-2015-102054

Nohe, C., \& Sonntag, K. (2014). Work-family conflict, social support, and turnover intentions: A longitudinal study. Journal of Vocational Behavior, 85(1), 1-12. https://doi.org/10.1016/j.jvb.2014.03.007 
Olson, R., Crain, T. L., Bodner, T. E., King, R., Hammer, L. B., Klein, L. C., ... \& Buxton, O. M. (2015). A workplace intervention improves sleep: results from the randomized controlled Work, Family, and Health Study. Sleep Health, 1(1), 55-65. https://doi.org/10.1016/j.sleh.2014.11.003

Pecino, V., Mañas-Rodríguez, M. Á., Díaz-Fúnez, P. A., AguilarParra, J. M., Padilla-Góngora, D., \& López-Liria, R. (2018). Interpersonal justice climate, extra-role performance and work family balance: A multilevel mediation model of employee well-being. PloS One, 13(11), e0207458. https://doi.org/10.1371/journal.pone.0207458

Posard, M. N., Hultquist, M., \& Segal, D. R. (2013). Adjusting the duty day schedule to improve health and family life in garrison. Journal of Human Behavior in the Social Environment, 23(6), 789-799.

https://doi.org/10.1080/10911359.2013.795086

Shapiro, S. L., Carlson, L. E., Astin, J. A., \& Freedman, B. (2006). Mechanisms of mindfulness. Journal of Clinical Psychology, 62(3), 373-386. https://doi.org/10.1002/jclp.20237

Slutsky, J., Chin, B., Raye, J., \& Creswell, J. D. (2019). Mindfulness training improves employee well-being: A randomized controlled trial. Journal of Occupational Health Psychology, 24(1), 139-149. https://doi.org/10.1037/ocp0000132

Smith, T. D., Hughes, K., DeJoy, D. M., \& Dyal, M. A. (2018). Assessment of relationships between work stress, work-family conflict, burnout and firefighter safety behavior outcomes. Safety Science, 103, 287-292. https://doi.org/10.1016/j.ssci.2017.12.005

Valcour, M. (2007). Work-based resources as moderators of the relationship between work hours and satisfaction with workfamily balance. Journal of Applied Psychology, 92(6), 1512. https://doi.org/10.1037/0021-9010.92.6.1512

Vieira, J. M., Matias, M., Lopez, F. G., \& Matos, P. M. (2018). Work-family conflict and enrichment: An exploration of dyadic typologies of work-family balance. Journal of Vocational Behavior, 109, 152-165.

https://doi.org/10.1016/j.jvb.2018.10.007
Wang, M., Kwan, H. K., \& Zhou, A. (2017). Effects of servant leadership on work- family balance in China. Asia Pacific Journal of Human Resources, 55(4), 387-407. https://doi.org/10.1111/1744-7941.12122

Wayne, J. H., Randel, A. E., \& Stevens, J. (2006). The role of identity and work-family support in work-family enrichment and its work-related consequences. Journal of Vocational Behavior, 69(3), 445-461. https://doi.org/10.1016/j.jvb.2006.07.002

Weinzimmer, L. G., Baumann, H. M., Gullifor, D. P., \& Koubova, V. (2017). Emotional intelligence and job performance: The mediating role of work-family balance. The Journal of Social Psychology, 157(3), 322-337. https://doi.org/10.1080/00224545.2016.1208141

Wilson, M. G., Polzer-Debruyne, A., Chen, S., \& Fernandes, S. (2007). Shift work interventions for reduced work-family conflict. Employee Relations, 29(2), 162-177. https://doi.org/10.1108/01425450710719996

Work, family \& health network (2020, February 10). Toolkits to achieve workplace change. https://workfamilyhealthnetwork. org/toolkits-achieve-workplace-change

Zarei, S., Esmaeili, M., Salimi Bajastani, H., \& Farahbakhsh, K. (2016). Effect of work-family conflict management model in life satisfaction of male employees. Journal of Research and Health, 6(5), 530-536. https://doi.org/10.18869/acadpub.jrh.6.5.530

Zhang, Y., Xu, S., Jin, J., \& Ford, M. T. (2018). The within and cross-domain effects of work-family enrichment: A metaanalysis. Journal of Vocational Behavior, 104, 210-227. https://doi.org/10.1016/j.jvb.2017.11.003

Zhao, K., Zhang, M., Kraimer, M. L., \& Yang, B. (2019). Source attribution matters: Mediation and moderation effects in the relationship between work-to-family conflict and job satisfaction. Journal of Organizational Behavior, 40(4), 492-505. https://doi.org/10.1002/job.2345 